\title{
Şeyhülislam Kemalpaşazâde'nin Cinler Hakkında Manzum Fetvâsı ve Ahlât-ı Erbaa Açısından Tahlili
}

\author{
Muhittin ELİAÇIK*
}

\begin{abstract}
ÖZ
Osmanlı'da ilgi çekici kalem mahsullerinden birisi de manzum fetvâlardır. Osmanlı fetvâlarının çok büyük bir kısmı mensur olarak verilmiş, ancak içlerinde ciddî sayıda da manzum olarak verilenler bulunmuştur. Hiç şüphesiz fetvâların bu şekilde verilmesi Türk edebiyatının yeni bir nazım türü kazanmasına zemin hazırladı̆̆ı gibi, ulema arasında da renkli bir edebî ortamın oluşmasına katkıda bulunmuştur. Osmanlida verilen ve yazılan manzum fetvâların şeyhülislâm veya müftülere sualin nazmen yöneltilmesi sebebiyle verildiği gözlenmektedir. Yani bu fetvâlar resen manzum biçimde verilmemiş, daha çok herhangi bir konuda şair birisi veya şairliği bulunan bir devlet adamının bir müftü veya şeyhülislama suali manzum biçimde yöneltmesinden dolayı verilmiştir. Osmanlı'da manzum fetvâ vermiş şu ana kadar tespit edilen müftü ve şeyhülislamların sayısı ile manzum fetvâların beyit adedinin yüksek bir sayıya ulaştığ görülmektedir. Tabiî ki daha tespit edilmeyenlerin de bulunması yüksek bir ihtimal olduğundan hepsi bir araya getirildiğinde hacimli bir kitapla tanıtılacak kadar geniş bir manzum fetvâ hazinesi ortaya çıkacaktır. Osmanlı'da şu ana kadar tespit edilen manzum fetvâ sayısı 60 civarında olup bunların beyit sayıları yaklaşık 500'dür. Bu fetvâlar içinde sadece tek mısradan ibaret olanları bulunduğu gibi, 64 beyitten oluşanları da bulunmaktadır. Hatta müstakil bir risale sayılabilecek olanlar da vardır. Yaklaşık 1520'li tarihlerde başladığı tahmin edilen Osmanlı manzum fetvâlarının içinde Arapça ve Farsça olarak verilmiş olanlar da bulunmaktadır. Osmanlı'da manzum fetvâların ilk örneklerinin ünlü Şeyhülislâm Kemalpaşazâde Ahmed
\end{abstract}

Prof. Dr., Kırıkkale Üniversitesi, Fen Edebiyat Fakültesi, Türk Dili ve Edebiyatı Bölümü, Kırıkkale/Türkiye E-posta: meliacik63@yahoo.com, ORCID: 0000-0002-5137-3275,DOI: 10.32704/erdem.948839 Makale Gönderim Tarihi: 18.08.2020 * Makale Kabul Tarihi: 26.03.2021 * (Araştırma Mk.) 
tarafindan verildiği söylenebilir. Osmanlı manzum fetvâ geleneğinin öncü isimlerinden birisi olan Kemalpaşazâde çok yönlü bir âlim olup filolojik çalışmaları da vardır. Osmanlı'nın zirve yüzyılına damga vurmuş birkaç büyük şeyhülislâmdan birisi olan bu zat birçok konuda fetvâ vermiş ve bunlar arasında dil ve edebiyat konuları da yer almıştır. Mürettep bir divanı da olan bu mühim sima esrar, şarap, afyon, raks, devran gibi, o devrin hassas ve tartışmalı birçok konusunda fetvâ vermiştir. Bu fetvâlar bazı aykırı ve çelişkili görüşler taşıdığından başka şeyhülislâmlarca düzeltilip açıklamalar yapılmıştır. Özellikle esrar hakkında verdiği manzum fetvâ çok tartı̧̧ılmış ve Ebussuud Efendi tarafından yorumlanmıştır. Onun manzum fetvâları arasında bir de cinler hakkında verdiği fetvâ vardır ki şekil, muhteva ve cinlerin tanımı bakımından oldukça ilgi çekicidir. Bu fetvâ, eski tıp anlayışındaki ahlât-1 erbaa teorisi ile de yakından ilişkili olup ins ile cin münasebetlerini vücut kimyası bağlamında açıklamaktadır. Bu çalışmada bu manzum fetvâ analitik biçimde incelenip tanıtılmaktadır.

Anahtar kelimeler: Kemalpaşazâde, şeyhülislâm, manzum fetvâ, cin, ahlât-1 erbaa 


\title{
A Poetry Fatwa of Sheikhulislam Kemalpashazade About the Gins. Analysis in Terms of Ahlât-1 Erbaa
}

\begin{abstract}
One of the interesting pen products in the Ottoman Empire is verse fatwas. Most of the Ottoman fatwas were given in prose, but a significant number of them were found in verse. Undoubtedly, giving fatwas in this way prepared the ground for Turkish literature to gain a new type of verse and contributed to the formation of a colorful literary environment among the ulema. It is observed that the verse fatwas given and written in the Ottoman Empire were given by the sheikh al-Islam or muftis because the question was directed in verse. In other words, these fatwas were not given ex officio in verse, but rather because a poet or a statesman who was a poet on any subject asked a mufti or sheikh al-Islam in verse. It is seen that the number of muftis and sheikh al-islams who have given verse fatwas in the Ottoman Empire and the number of couplets in verse fatwas reached a high number. Of course, since there is a high probability that there will be some that have not yet been identified, when all of them are brought together, a verse treasury that is large enough to be introduced with a voluminous book will emerge. The number of verse fatwas determined so far in the Ottoman Empire is around 60, and the number of couplets is about 500. Among these fatwas, there are some that consist of only one verse, as well as those that consist of 64 couplets. It can even be said that there are some that can be considered as a separate treatise. Among the Ottoman verse fatwas, which are estimated to have begun around 1520, there are also those given in Arabic and Persian. It can be said that the first examples of verse fatwas in the Ottoman Empire were given by the famous Şeyhülislâm Kemalpaşazâde Ahmed. One of the pioneers of the Ottoman poetic fatwa tradition is Şeyhülislâm Kemalpaşazâde Ahmed, a versatile scholar. This person, who was one of the few great sheikhulislams that marked the peak century of the Ottoman Empire, gave fatwas on many issues, and language and literature were among them. This important figure, who was also a divan of mürettep, gave fatwas on many sensitive and controversial issues of that period such as cannabis, wine, opium, raks, and devran. Since these fatwas have some contradictory views, they were corrected and explained by other Shaykh al-Islams. Especially the verse fatwa he gave about cannabis was discussed a lot and was interpreted by Ebussuud Efendi. Among the verse fatwas, there is also a fatwa he gave about jinn, which attracted attention in terms of shape, content and definition of jinn. This fatwa is also related to the theory of
\end{abstract}


humoral pathology in the old medical understanding and explains the relationships between humans and jinn in the context of body chemistry. In this study, this verse fatwa is analyzed and introduced analytically.

Keywords: Kemalpashazade, sheikhulislam, poetry fatwa, jinn, humoral pathology. 


\section{Giriş}

I slam dünyasında eser telif ve tercümelerinde manzum biçim sıklıkla görülen bir uygulama olup buna fetvâlar da dahil olmuştur. Çeşitli devirlerde birçok fetvâ manzum biçimde de verilmiş ve Osmanlı'da ise bu uygulama 16. yüzyılın ortalarından itibaren görülmeye başlanıp, yüzyılın sonlarında manzum fetvâlarda bir de Hocazâde ailesi geleneği oluşmuştur. Fetvâlarda manzum biçimin de kullanılışı genellikle şeyhülislâm veya müftünün şairliğinden kaynaklanmış ise de her şairliği bulunan mutlaka manzum fetvâ vermiş değildir. Bu durum daha ziyade meselenin manzum biçimde sorulmasıla ilgili olmuştur. Osmanlı'da manzum fetvâ veren şeyhülislâmların en önde gelenleri Kemalpaşazâde, Sadullah Sadi, Ebussuud, Hoca Sadeddin ve Muhammed Bahai Efendiler olup şu ana kadar 60 civarında manzum fetvâ tespit edilmiştir.

\section{Fetvâ}

Fetvâ; yiğit, genç, kavi manasındaki Arapça fetâ kökünden gelen bir sözcük olup, fikhi manada herhangi bir konuda bir güçlüğün çözümü için soru sorana verilen güçlü cevaptır. Verilen fetvâ ile bir olayın hüküm ve cevabı ortaya konulup mesele güçlü biçimde çözülmüş olduğundan bu isim verilmiştir (Asım 1305: 895). En önemli işi fetvâ vermek olan şeyhülislâmlık makamı Osmanlı Devleti'nde 15. yüzyılın başlarında kurulmuş; vilâyet, sancak ve kazalarda da müftüler bu makama bağlı olarak görev yapmış, özel hukuku ilgilendiren fetvâlar kişilerin, kamu hukukunu ilgilendiren fetvâlar da idarecilerin isteği üzerine verilmiştir. Osmanlı döneminde müftüler öncelikle Hanefî mezhebinin zâbirür-rivâye kitaplarından görüşleri almışlar ve mukallit müftülere yardımcı olmak için şeyhülislâm ve müftülerin fetvâları kendileri veya başkalarınca kitap hâline getirilmiştir (Atar 1995: 486-496).

\section{Manzum Fetvâ}

Osmanlı'da fetvâlar genellikle mensur yazılmakla birlikte onların az sayıda da olsa manzum biçimde verilenleri de olmuştur. Bu fetvâlar genellikle şairliği bulunan şeyhülislâm veya müftülerce verilmiş ve manzum verilmesine soruyu soran sebep olmuştur. Osmanlı'da manzum fetvâlar 16.yüzyılın ortalarında görülmeye başlamış ve ilk temsilcileri Kemalpaşazâde, Sadullah Sadi Çelebi ve Ebussuud Efendi olmuştur. Bu yüzyılın sonunda Hoca Sadeddin Efendi ile oğul ve torunları arasında aile düzeyinde manzum fetvâ geleneği de oluşmuştur. Osmanlı manzum fetvâları edebî yönden iddialı olmayıp, kıta 
şeklinde ve kısa aruz kalıplarıyla yazılmış, belli bir tertipte kaleme alınmıştır. Bu fetvâları şeyhülislâmlardan başka müftü ve kadılar da verebilmiştir. Manzum fetvâlar bazen mektup veya nasihatnâme tarzında da verilebilmiştir. Osmanlı manzum fetvâ geleneğinin öncülerinden birisi de Şeyhülislâm Kemalpaşazâde'dir.

\section{Kemalpaşazâde (İbn Kemal Ahmed)}

Asıl adı Şemseddin Ahmed olup, dedesi Kemal Paşa'dan dolayı İbn Kemal veya Kemalpaşazâde diye tanınmıştır. 1469 'da Tokat veya Amasya'da doğmuş, ilk tahsilini Tokat ve Amasya'daki görevleri sırasında babasından, sonra hocası Molla Kestelîden almış, ardından dersler vermeye başlamıştır. Hocas1 Müeyyedzâde Anadolu kazaskeri olduğunda İstanbul'da Taşlık Medresesi müderrisliğine atanmış, Türkçe bir Osmanlı tarihi yazmakla görevlendirilmiş, Balkanlarda çeşitli yerlerde görevler yaptıktan sonra sırayla Edirne Halebiye ve Üç Şerefeli, İstanbul Sahn-1 Seman ve Edirne Sultan Bayezid medreselerinde müderris olmuş, 1515'te Edirne kadisı, 1516'da Anadolu kazaskeri olmuş, bu görevdeyken Sultan Selim'in Misır seferine katılıp Misır'ın, daha sonra da Karaman'ın yeniden tahririyle görevlendirilmiştir. 1526'da Şeyhülislâm Zenbilli Ali Efendi'nin vefatı üzerine şeyhülislâm olmuş ve bu görevdeyken 16 Nisan 1534'te İstanbul'da vefat etmiştir. Çok yönlü bir âlim olup tefsir, hadis, fikıh, tarih, edebiyat, felsefe, dil, tıp gibi alanlarda birçok eser yazmıştır (Turan vd., 2002: 238-247). Mürettep bir divanı yanında yazma nüshalarda nasihatnâme türü pek çok manzumesi yer almaktadır. Fetvâları arasında şaka yollu söylenmiş, tartışma ve çelişkilere sebep olmuş konular da olup bunlardan özellikle esrar hakkındaki fetvâsı birçok tashih ve yoruma sebep olmuştur.

Kemalpaşazâde'nin fetvâları yazma nüshalarda Ahmed, Ahmed ibn Kemâl, İbn Kemâl imzalarıyla geçmekte, bazen de Ebussuud Efendi'nin fetvâları ile iç içe bulunmaktadır. Bazı fetvâları Hanefîliğe aykırı görüşler içerdiğinden başka şeyhülislâmlarca, özellikle de Ebussuud Efendi tarafindan yorumlanarak düzeltilmiştir. Mesela bir fetvâsında kişiyi hezeyana götürmeyecek kadar esrar içmenin haram olmadığını söylemiş, diğerinde ise az veya çok keyif için esrar içmenin haram olduğunu bildirmiştir. Devran, sema ve raks hakkında da birçok fetvâ vermiş ve bunları genellikle sert sözlerle reddetmiştir.

\section{Kemalpaşazâde'nin Manzum Fetvâları}

Mürettep bir divan sahibi çok yönlü bir âlim olan Kemalpaşazâde dil ve edebiyat konularında pek çok eser ve fetvâ verdiği gibi, Arapça ve Farsça olarak da 
birçok şiir yazmıştır. Manzum fetvâları yazma nüshalarda sık geçmemekte ise de çok sayıda manzum fetvâ verdiği bilinmektedir. Şu ana kadar üç adet manzum fetvâsı tespit edilmiş olup bu sayının daha da artacă̆ı tahmin edilmektedir. Fetvâları genel olarak kısa, sade Türkçeyle, tasannusuz ve bazıları şaka, nükte ve tarizkâr ifadeler bulunan metinlerdir. Kendisi için insanlarla cinlerin müftüsü (sakaleyn) lakabı kullanılmıştır. Tespit edilen manzum fetvâları esrar, talak ve cinler hakkında olup bunlar ayrı bir çalışmada tanıtılmıştır (Eliaçık 2020:74-83). Bu çalışmada ise önemine binaen cinlerle ilgili fetvâ müstakil olarak ele alınıp ahlât-1 erbaa açısından analitik bir inceleme yapılmaktadır.

\section{Cinlerle ilgili manzum fetvâ ve ahlât-1 erbaa açısından tahlilii ${ }^{1}$}

Su'âlü Mevle'l-fâzıli'l-Fudayli'l-Cemâlî ilâ Hazreti'l-allâmeti'bni'l-Kemâl rabimehuma'llahu ta'âlâ

\section{Fe'ilâtün fe'ilâtün fe'ilâtün fe'ilün}

1 Bir suâlüm var eyâ Hazret-i Müfti’s-sakaleyn

İns ile cinne fazîletle virürsin fetvâ

2 Hürmet-i Hazret-i Sultân-1 Resûlü's-sakaleyn

Lutfunile bize keşf ola bu sırr-1 ahfâ

3 Hikmetin sûret-i fetvâda nümâyân eyle

Hilkat-i nârda şahsiyyet olur mı peydâ

4 Yâ ne sûretle nümâyân ola inse cinnî

Unsuriyyetle mutayyeb degil anlar nev'â

5 Rû-nümâ ola mı size taleb-i fetvâda

Yohsa hikmetle kelâmın mı idersiz ısgâ

6 Eyleniz bize bu esrâr-1 hafâyâyı beyân

İctihâd-1 hikemün ide ziyâde Mevlâ

Cevâbu Mevle'l-fâzıli'l-allâme Hazreti İbni Kemâl aleybi rahmetül Müte'âl

1 Dinle ey sâil-i cin-fikret-i insî-fitnat

Tâ nümâyân idem esrâr-1 hafâyâyı sana

2 Âbdest içre cevârihle olur emr-i vuzû

Âb hod zıddıdur ol âteşi eyler 1 tfâ

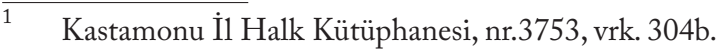


3 Hem ibâdetde ikâmetle rükû' u secde

Kim tahiyyetle selâmile olur Hakka senâ

Velehu

1 Ünsi var insile cinnün cihet-i câmi’ada

Cihet-i uzvile tertîb-i salât olur edâ

2 Size bunlar görinür mi diyü olursa su'âl

Görinürden dahi çok bunda görünmez ma’nâ

Ey ins ve cinnin müftüsü, sana bir sualim var, Hazret-i Resûl bürmetine bize bu çok gizli sırr lütfet de bir açıla ve bikmetini fetvâ sûretinde göster: Ateşin yaratılışında şabsiyet görünür mü veya inse cin taifesi nasil görünür? Onlar tür olarak cismaniyetle (maddi yapıyla) taltif olunmus olmadiğından sizden fetvâ istediklerinde size görünürler mi, yoksa siz bikmetle onların sözlerini mi işitirsiniz? Bize bu gizli sırları güzelce açıklayın. Mevlâ, bikmetli çalısmalarınızı artırsın.

Büyük âlim İbn Kemâl'in cevabı:

Ey bu suali soran cin fikirli, insan yaratıllş̧l kişi, dinle de sana bu gizli sırları açıklayayım: Abdest işi, abdestin içindeki cevârih (el, kol, ağı gibi uzuvlar) ile olur ve ateşin zıdda da su olup onu söndürür. İbâdetteki Hakk'a senâ da ikamet, rükû, secde, tahiyyet ve selâmla olur.

Diğer: İns ile cinnin bütün olarak yakınlığı ve arkadaşlığı vardır; namazın tertibi de uzuvlarla eda edilmektedir. Eğer size bunlar görünür mü diye sorarsan, bundaki görünmez mana, görünenden daha çoktur.

Bu fetvâda, 'eşyanın tabiatı zıtlıkla kaimdir' kaidesince insanlarla cinler arasındaki ilişki, abdest ve namaz örneğinden hareketle açıklanmıştır. Buna göre abdest, ateşin bir nevi aracı olan cevarihi teskin ederek Hakk’a ibadeti sağlamaktadır. Yani suyu temsilen insan ile ateşi temsilen cin, birbiriyle uyumlanarak Rablerine kulluk etmektedirler. Burada görünmeyen mana, görünen manadan daha çoktur. Bu fetvâ, ahlât-1 erbaa ile de ilgilidir.

\section{Ahlât-1 Erbaa (Humoral Patoloji)}

Ahlât-1 Erbaa, eski tıp anlayışında insanın davranışlarını etkilediği kabul edilen, insan bedenindeki kan, safrâ, sevdâ ve balgama dört karışım (sıvı) anla- 
mında verilen ad olup, hastalık bu dört sıvının bedendeki dengesizliğinden ortaya çıkmaktadır. Eski Mısır'da hekimler hastalı̆̆ın sebebi olarak bünyedeki bu dört sıvının kirlenmesini görmüş ve tedavide kirli sıvıları boşaltmışlardır. Sicilyalı Empedokles, Phythagoras'ın dörtlü ritim teorisine dayanıp evrenin ateş (kuru-sıcak), hava (yaş-sıcak), su (yaş-soğuk), toprak (kuru-soğuk) şeklinde birbirine zit dört öğeden oluştuğunu öne sürmüş, bu teoriyi de Hippokrates insan bedenine uygulayarak humoral patoloji teorisi ortaya çıkmıştır. Bu teoriye göre bedende dört sıvı denge içindedir ve birinin artması veya eksilmesinden hastalık ortaya çıkmakta; sevdânın dengesizliği aklî ve psikolojik hastalıkları; kanın dengesizliği kan hastalıklarını; safrânın dengesizliği karaciğer ve böbrek hastalıklarını; balgamın dengesizliği de istiska vb. hastalıkları ortaya çıkarmaktadır. İlkbaharda kan, yazın safrâ, sonbaharda sevdâ, kışın balgam harekete geçmektedir. Bu sıvılar insanların karakterlerini de etkilediğinden safrâvî (colérique), sevdâvî (mélancolique), demevî (saanguin), balgamî (flegmatique) şeklinde psikolojik tiplemeler ve mahrûr (kan/sıcak tabiatlı), mebrûd (safrâ/soğuk tabiatlı), yâbis (sevdâ/kuru tabiatlı), mertûb (balgam/yaş tabiatlı) şeklinde karakter tasnifleri ortaya çıkmıştır. Bu teori antik Yunan tıbbında humoral patoloji, İslam tıbbında ise ahlât-1 erbaa adıyla bilinmekte olup, İbn Sina tarafindan hissî ve zihnî durumlarla tavır ve rüyalar da eklenerek genişletilmiştir (Erdemir 1989: 24; Eliaçık 2010: 130131).

Ahlât-1 erbaa Türk şiir ve edebiyatının önemli unsurlarından olup Fuzulî̀nin Sıhhat u Maraz’ı gibi, bu teoriye göre kurgulanıp yazılmış eserler de vardır. Kemalpaşazâde'nin fetvâsında da bu teoriyi ilgilendiren hususlar bulunmakta olup bunlar maddeler hâlinde aşağıdaki gibi sıralanabilir:

1. Kemalpaşazâde büyük bir şeyhülislâm olarak sadece insanların değil, müfti’s-sakaleyn lakabıyla cinlerin de müftüsü olarak kabul edildiğinden cinlerin kendisiyle nasıl konuşup soru sorduğu merak edilmiştir.

2. Ateşten yaratılan cinler için: "Ateşin yaratılışında şahsiyet görünür mü; değilse cin taifesi cismaniyetle (maddi yapıyla) taltif olunmadığından insana nasıl görünebilir? Sizden fetvâ istediklerinde görünürler mi, yoksa siz hikmetle sözlerini mi duyarsınız?" diye sorulmuştur. Burada cin taifesinden şeytanın: 'Ben ateşten, insan ise topraktan yaratıldı' diyerek Âdem'e secde etmemesine telmih yapılmış olmalıdır.

3. Kemalpaşazâde cevabında vücut kimyasının zıtlık yönüne atfen abdest ve namaz örneğini vermiş ve suali soran kişiye 'cin fikirli, insan 
yaratılışli' demekle bu sualin ancak böyle birisince sorulabileceğini anlatmıştır. Cevapta: 'Abdest içinde abdest işi cevârib ${ }^{2}$ ile olur; su da ateşin zıddr olduğundan onu söndürür. İbadette Hakk'a senâ da ikamet, rük $\hat{u}$, secde, tabiyyet ve selâm ile olur.' demekle vücuttaki zit unsurların abdest ve duayla mutabakat üzere olacağını kastetmiştir. Burada suç ve günahların işlendiği, cinnin de yerleştiği uzuvlar olduğundan cevârihe ateş denilmiştir ve ateş de su ile söndürülür. Bu cevapta aynı manadaki Arapça vuzûu ve Farsça âbdest kelimelerinin kullanılması da anlamlı olup, 'temizlenme, el suyu vasıtasıyla cevarih ile gerçekleşir' denilmiştir. Bedende zitlık üzerine kurulu bir sistem bulunduğundan bunlar önce abdestle teskin edilip, sonra huzurla Hakk'a ibadet gerçekleşmektedir.

4. Cevarih denilen el, ayak, ağız gibi uzuvlar bedende kanın yoğun bulunduğu uç noktalarda olup öldürme, yaralama gibi suçların da büyük ölçüde bunlarla işlendiği görülmektedir. Kanın yoğunlaştığı bu uzuvlarda ateşten yaratılmış cin taifesinden şeytan rahatça dolaşmakta, kanın merkezi olan kalp ve damarlarda da tünemiş vaziyette beklemektedir. $\mathrm{Bu}$ bakımdan şeytanın insana vesvese verdiği kalpteki fisıltı merkezine lümme-i şeytânî denilmiştir. Bu husus bir hadîs-i şerîfte: Şeytan insanoğlunun kalbinin üzerinde tünemis vaziyette bekler. Allab’ zikredince siner, çekilir; gaflet etse vesvese verir." (Canan 1988: 3/316) şeklinde açıklanmış, bir başka hadiste de: "Kocası gurbette olan (yabancı) kadınların yanına girmeyin. Zira şeytan, herbirinizin içinde, vücudunuzda kanın dolaştığ gibi (kendisini hissettirmeden) dolaşır. Bende de (dolaşır), ancak Allab bana yardım etti de (şeytanım) müslüman oldu." (Canan 1988: 7/118) denilmiştir. Dolayısıyla abdestle, cevarihte yerleşmiş olan ateş tabiatlı cin taifesi teskin edilerek insanla barışı hâle getirilmekte, namazla da iyice insanla kaynaşmaktadır. İşte bu, insle cinnin arkadaşlı̆̆ı olmaktadır.

5. Fetvâya göre cinlerin ahlât-1 erbaa açısından karş1lı̆̆1 ateş olup yeri ise cevarihte bulunan kandır. Ahlât-1 erbaada kâinattaki dört unsur ikişerli grup hâlinde birbirinin zıddı olup suyun zıddı da ateştir. Aslında dört

Bu konuda Mütercim Asım şu bilgiyi vermiştir: "Cervârih kazanç elde etmek manasındaki Arap̧̧a cerb kökünden gelen bir kelime olup câribanın çoğuludur ve kazanılan bir şeydeki tesirinden dolay insanin el ve ayaklarına cevârih denilmiştir. Ayrıca, birisine sövüp sayıp incitmek manasında da kullanılır ki kılıç yarasından daba şiddetlidir. Ayruca, sabiplerine mal kazandırdıkları için kısraklara da bu ad verilmiştir. Insanın kazanç elde eden uzuvları da büyük ölçüde el ve ayakları olup buna ağız da dabil edilmiştir. Çünkü büyüklerin nedimleri gibi, bazı laf ebeleri söz satıp para kazanırlar. Tayıncı puștların kıçları da buna dabildir. Avcı olan yırtıcı kușlara ve canavarlara da cevarih denilmiştir." (Asım 1305: 461). 
unsurun aslının su olduğu ve her şeyin sudan yaratıldığı görülmektedir. ${ }^{3}$ İnsan bedenindeki dört sıvı balgam, kan, safrâ, sevdâ olup suyun karşılı̆̆ ise balgamdır. İnsan vücudunun \%60'ının sudan oluştuğu ve balgamın da suyun en yoğun olduğu uzuvlardan beyin ve akciğerde bulunduğu görülmektedir. Ahlât-1 erbaaya göre ateşin vücuttaki karşllı̆̆ safrâ, havanınki de kandır (Eliaçık 2010: 130-132). Bu fetvâda kan ile ateşin eşleştirilerek su ile teskin edildiği görülmektedir. Bilindiği üzere ateş, bedendeki bir enfeksiyona bağı̧̧ıklık sisteminin tepki göstermesidir ve vücut 1 sısı yükselerek hastalığa yol açan organizmalar yok edilmeye çalışılmaktadır. Bu ise kan yoluyla gerçekleşen bir olay ve ateşin yerinin kan olduğunu tekit eden bir durumdur. Buna göre cevarihi de canlandırıp azdıran kandaki ateş olmaktadır.

6. “Cinler cismaniyetle taltif olunmuş değilken (maddi yapıya sahip olmayan ruhaniler iken) insana nasıl görünür?” sorusuna gelince: Yukarıda bahsedildiği üzere, abdestle cevarihte yerleşmiş olan ateş tabiatlı cin taifesi (bir yönden şeytan) teskin edilmekte, namazla da iyice insanla alışıp kaynaşmaktadır. İşte bu, ins ile cinnin arkadaşlığı olup görüşüp konuşma da uzuvların namaz tertibi üzere böylece temiz ve huzurlu olmasılla sağlanmaktadır. Buna göre, görünmeyen mana, görünenden daha çoktur.

3 “İnkâr edenler, göklerle yer bitişikken, bizim onları ayırdığımızı ve diri olan her şeyi sudan meydana getirdiğimizi görmediler mi? Hâlâ inanmayacaklar mı?” Kuran-1 Kerim Enbiya sûresi 30. ayet. 


\section{Sonuç ve Değerlendirme}

$\mathrm{Bu}$ çalışmada, önde gelen Osmanlı şeyhülislâmlarından birisi olan Kemalpaşazâde'nin dikkat çekici bir fetvâsı incelenmiştir. Gerek nazmen verilmiş olması, gerekse muhtevası itibarıyla önemli olan bu fetvâ, Doğu'da ahlât-1 erbaa, Batı'da ise humoral patoloji adı verilen sisteme paralellik göstermektedir. Bu fetvânın konusu, Şeyhülislam Kemalpaşazâde'nin cinlerle nasıl görüştüğü üzerine kurulmuştur. $O$ ise bu görüşmeyi su ile ateşin zitlığ1na dayanarak açıklamıştır. Buna göre ateşten yaratılan cin taifesi (bir bakıma kanda dolaşan şeytan) su ile yatıştırılıp kaynaştırılmakta, sonra da dua (namaz) ile kardeşliğe dönüştürülmektedir. Böylece ateşten yaratılmış olan cin taifesi ile insan bedeninde nasıl bir görüşme olduğu gösterilmiş olmaktadır. Ahlât-1 erbaa unsurları insan bedeninde de şekil itibarıyla tıpkı kânattaki zıtlığın bir yansıması olarak bulunmaktadır. "Su-toprak-hava-ateş" şeklinde sıralanan dört unsur, zit olmakla beraber tam bir uyum içindedir. Osmanlı'da 16.yüzyılın ortalarından itibaren görülmeye başlanan manzum fetvâların öncü isimlerinden olan Kemalpaşazâde kendisine sorulan sorulara nükte ve ince manalarla cevaplar vermiştir. Bazı meseleler kendisine elit meclislerde nükteli ve şaka yollu ifadelerle manzum biçimde sorulmuş, o da aynı yolla bazen de eleştiri ve kınayıcı bir üslupla cevap vermiştir. Bu çalışmada incelenen cinlerle ilgili manzum fetvâsı bu yönlerden de ilgi çeken, ama asıl önemini ahlât-1 erbaa açısından alan bir fetvâdır. Bu fetvâ, kendi devrinde ins ve cinnin müftüsü olarak tanınmış olan Kemalpaşazâde'nin cinlerin insan bedenindeki yeri ve teskin ediliş biçimine dair verdiği bilgilerce önemlidir. $\mathrm{Bu}$ fetvâ, ahlât-1 erbaa açısından analitik biçimde incelenmekle fetvâların ne gibi konuları içerebildiği de gösterilmiş olmaktadır. Her biri çok yönlü birer âlim olan Osmanlı şeyhülislâm ve müftüleri tıp konusunda da bilgili olduklarını her firsatta göstermişlerdir. Şeyhülislâm Kemalpaşazâde, cinlerle nasıl konuştuğuna dair kendisine yöneltilen soruya verdiği cevapta vücut kimyasını eski tıp anlayışı içinde yorumlayarak ustaca bir cevap vermiştir. Fetvânın cevabında geçen 'Görünmeyen mana, görünenden daha çoktur.' ifadesi, söz konusu ruhani varlıkların şeyhülislama meselelerini çoğu zaman görünmeksizin tevcih ettiklerini, ama bazen de görünebildiklerini zımnen anlatmaktadır. 


\section{KAYNAKLAR}

Atar, F.(1995). “Fetvâ”, TDVİA, C.XII, s. 486-496, İstanbul: TDV Yayınlar1. Canan, İ. (1988). Kütüb-i Sitte Tercüme ve Şerbi, Ankara: Akçă̆ Yayınları.

Çelebi, İ. (2002). “Kemalpaşazâde”, TDVİA, c. 25, s. 245-247, İstanbul: TDV Yayınları.

Eliaçık,M.(2010). “Sıhhat u Maraz'da Ahlât-1 Erbaanın İşlenişi”,Mukaddime 1/1, s. 125-141.

Erdemir, A. D. (1989). "Ahlât-1 Erbaa”, TDVİA, c. 2, s.24, İstanbul: TDV Yayınları.

Kuran-ı Kerim Meâli (2011). (Hazırlayanlar: Halil Altuntaş - Muzaffer Şahin). Ankara: Diyanet İşleri Başkanlığı Yayınları.

Mütercim Asım (1305). Kamus Tercümesi, İstanbul: Matbaa-i Osmaniye.

Özen, Ş. (2002). “Kemalpaşazâde”, Diyanet İslam Ansiklopedisi, c. 25, s.240242, İstanbul: Türkiye Diyanet Vakfi Yayınları.

Saraç, M. A. Yekta. (2002). "Kemalpaşazâde”, TDVİA, c. 25, s. 244-245, İstanbul: TDV Yayınları.

Turan, Ş. (2002). “Kemalpaşazâde”, TDVİA, c. 25, s. 238-240, İstanbul: TDV Yayınları.

\section{Yazma Eserler}

Mecmûatül-fetâvâ, Diyanet İşleri Başkanlığg1 Kütüphanesi, No: 001923, Ankara.

Milli Kütüphane Yazmalar Koleksiyonu:

Risâle-i Akâid, No: 06 Mil Yz A 9135.

Fetâvâ, 06 Mil Yz A 7975/2.

Fetâvâ, 06 Mil Yz A 8661.

Kanunnâme, 06 Mil Yz A 5010.

Kastamonu İl Halk Kütüphanesi, No: 3753.

Balıkesir İl Halk Kütüphanesi, No: 10 Hk 1108. 
